\title{
PERFIL PROFISSIONAL TENDO O SUS COMO BASE DAS DIRETRIZES CURRICULARES DA ÁREA DA SAÚDE NO PROCESSO AVALIATIVO
}

\author{
Professional profile having SUS as base of curriculum guidelines area \\ haelth in the process evaluative
}

\section{Suzana Schwerz Funghetto}

Educadora Especial. Doutoranda do Programa de Programa de Pós-Graduação Stricto Sensu de Ciências e Tecnologias em Saúde, da Universidade de Brasília, Faculdade de Ceilândia, Distrito Federal.

E-mail: sfsuzana@gmail.com

\section{Sueli Macedo Silveira}

Pedagoga. Servidora do Instituto Nacional de Estudos e Pesquisas Anísio Teixeira. Coordenadora de Avaliação de Cursos e Instituições de Ensino Superior. Diretoria de Avaliação da Educação Superior. E-mail: sueli.silveira@inep.gov.br

\section{Alexandre Magno Silvino}

Psicólogo, mestre e doutor em Psicologia pela Universidade de Brasília. Pesquisador Tecnologista da Coordenação Geral de Avaliação da Diretoria de Avaliação da Educação Superior do Instituto Nacional de Estudos e Pesquisas Educacionais Anísio Teixeira do Ministério da Educação. Brasília, DF. E-mail: alexandre.silvino@inep.gov. $\mathrm{br}$

\section{Margo Gomes de Oliveira Karnikowski}

Farmacêutica. Professora doutora Programa de Programa de Pós-Graduação Stricto Sensu de Ciências e Tecnologias em Saúde, da Universidade de Brasília, Faculdade de Ceilândia, Distrito Federal.

E-mail:margo@unb.br

\section{Resumo}

O perfil profissional comum descrito nas diretrizes da área da saúde aponta para uma formação atrelada às necessidades da população, com a diversificação dos cenários de práticas e o fortalecimento da parceria e da interação entre ensino-serviço e comunidade, de acordo com os princípios do Sistema Único de Saúde (SUS). Tal discussão tem como base a concepção desse perfil construído a partir da necessidade uma formação generalista, humanista, crítica e reflexiva e o trabalho em equipe que atenda as necessidades de saúde da população brasileira. Este artigo traz algumas reflexões sobre a concepção de perfil profissional da área da saúde descrita nas Diretrizes Curriculares Nacionais (DCN) e os resultados obtidos na avaliação in loco previstos pelo Sistema Nacional de Avaliação da Educação Superior (SINAES). Foram realizadas análises descritivas em dados secundários de 1.048 avaliações no período de 2012 a 2014. Os resultados apontam para o papel da avaliação como indutora 
de qualidade no processo de construção dos projetos pedagógicos, bem como a necessidade de reflexão pela área sobre a concepção desse perfil profissional comum de acordo com os princípios do SUS, com a contextualização da formação em relação a região de saúde, com os problemas do país e as necessidades de conhecimento impostas pelo mundo moderno.

Palavras-chave: perfil, saúde, formação, avaliação, SUS, SINAES

\section{Abstract}

The common professional profile described in the directives of the area of the health points to a formation harnessed to the necessities of the population, with the diversification of the sceneries of practices and the strengthening of the partnership and of the interaction between teachingservice and community, in accordance with the beginnings of the Only System of Health (SUS). Such a discussion takes as a base the conception of this profile built from the necessity a formation general, humanist, critical and reflexive and the work in team who attends the necessities of health of the Brazilian population. This article brings some reflections on the conception of professional profile of the area of the health described in the National Curriculum Directives (DCN) and the results obtained in the evaluation in loco predicted by the National System of Evaluation of the Superior Education (SINAES). From 2012 to 2014 were carried out descriptive analyses in secondary data of 1.048 evaluations in the period. The results point to the paper of the evaluation like inducing of quality in the process of construction of the pedagogic projects, as well as the reflection necessity for the area on the conception of this common professional profile in agreement with the beginnings of the SUS, the contextualization of the formation regarding health region, with the problems of the country and the necessities of knowledge imposed by the modern world.

Keywords: profile, health, formation, evaluation, SUS, SINAES

\section{Introdução}

A discussão sobre a formação dos profissionais de saúde deve estar orientada, a partir dos preceitos constitucionais de 1988, para atender as mudanças paradigmáticas da área, tendo como foco o cuidado centrado no sujeito enquanto ser histórico e social, percebido em sua integralidade e ativo no processo de saúdedoença. ${ }^{1,2,3,4}$

Do Sistema Único de Saúde (SUS) emergem os princípios básicos para o ordenamento da formação de recursos humanos da área, uma vez que as ações de saúde como a universalidade de acesso; a integralidade de assistência; a preservação da autonomia das pessoas na defesa de sua integridade física e moral; a igualdade da assistência à saúde; o direito à informação divulgação de informações quanto ao potencial dos serviços de saúde e a sua utilização pelo usuário; utilização da epidemiologia para o estabelecimento de prioridades; a participação da comunidade; a descentralização político-administrativa; a integração dos das ações da saúde, o meio ambientee saneamento básico; a conjugação dos recursos financeiros, tecnológicos, materiais e humanos da União, dos Estados, do Distrito Federal e dos Municípios na prestação de serviços de assistência à saúde 
da população; a capacidade de resolução dos serviços de assistência; e organização para evitar duplicidade de meios para fins idênticos. ${ }^{\text {5:04 }}$

Para a concretização de mudanças no processo de formação dos profissionais que reflitam na melhoria das ações de saúde no SUS, foi necessário a parceria entre os setores da Saúde e Educação para que houvesse uma reforma curricular dos cursos de graduação que compõem a área.

O Conselho Nacional de Educação (CNE), por meio da Câmara de Educação Superior, é órgão responsável pela construção de diretrizes curriculares nacionais que visam expressar o conceito de qualidade expresso na Constituição de 1988, bem como orientar as instituições brasileiras de ensino na organização, articulação, desenvolvimento de suas propostas pedagógicas e de seus currículos. Esse conselho instituído pela Lei 9.131 de 1995 tem atribuições normativas, deliberativas e de assessoramento ao Ministro de Estado da Educação. 6:01

O processo de elaboração das diretrizes inclui análise das propostas constantes nos pareceres elaborados pelo CNE e submetidos à consulta da comunidade educacional, para que, após esse procedimento, sejam formalizadas em termos de resoluções, de caráter mandatório para todos os sistemas de ensino do território nacional e servem também de referência para os processos de avaliação dos cursos. ${ }^{7}$ As diretrizes dos cursos da saúde foram elaboradas pelas Comissões de Especialistas da Secretaria de Ensino Superior (SESU) do Ministério da Educação (MEC) e encaminhadas ao CNE em 2001 para que subsidiassem os pareceres e as resoluções dos cursos dos respectivos cursos graduação.

Após amplo debate ${ }^{i}$ com a

i Foi realizada, também em 2001, na sede CNE, uma audiência pública, para apreciação das propostas apresentadas pelas Comissões de Especialistas de Ensino da SESu/MEC, com a participação de comunidade educacional, científica, dos conselhos profissionais, dos trabalhadores da área da saúde e tendo como elementos básicos de estruturação a definição do perfil do egresso; as competências $e$ habilidades desejáveis; organização do curso, os conteúdos curriculares; os estágios $e$ as atividades complementares, acompanhamento e avaliação foram encaminhados pelo CNE $\mathrm{CN}^{\mathrm{ii}}$ os textos dos pareceres que fundamentaram as resoluções que constituíram-se em orientações para a elaboração dos currículos com competências

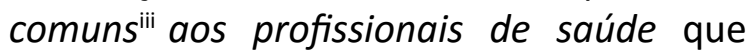
devem necessariamente ser adotadas por todas as instituições de ensino.

Em especial, cabe destacar que a concepção de uma formação generalista

representantes do Ministério da Saúde, Conselho Nacional de Saúde, Secretaria de Educação Superior do Ministério da Educação, Fórum Nacional de PróReitores das Universidades Brasileiras, Conselhos Profissionais, Associações de Ensino, e outras entidades organizadas da sociedade civil, como a Rede Unida.

ii OCNEanalisouaspropostas deDiretrizesCurriculares Nacionais dos Cursos de Graduação da área de Saúde elaboradas pelas Comissões de Especialistas de Ensino e encaminhadas pela SESu/MEC ao CNE, tendo como referência os seguintes documentos: Constituição Federal de 1988; Lei Orgânica do Sistema Único de Saúde № 080 de 19/9/1990;Lei de Diretrizes e Bases da Educação Nacional (LDB) № 394 de 20/12/1996; Lei que aprova o Plano Nacional de Educação № 172 de 9/1/2001;Parecer CES/CNE 776/97 de 3/12/1997;Edital da SESu/MEC № 4/97 de 10/12/1997;Parecer CES/CNE 583/2001 de 4/4/2001;Declaração Mundial sobre Educação Superior no Século XXI da Conferência Mundial sobre o Ensino Superior, UNESCO: Paris, 1998;Relatório Final da 11a Conferência Nacional de Saúde realizada de 15 a 19/12/2000;Plano Nacional de Graduação do ForGRAD de maio/1999;Documentos da OPAS, OMS, Rede UNIDA e Instrumentos legais que regulamentam o exercício das profissões da saúde.

iii A Rede Unida produziu em 1998 um texto preliminar encaminhado à SESU/MEC, onde formulou competências comuns aos profissionais de saúde. Este texto é conhecido como "Contribuição para as novas diretrizes curriculares dos cursos de graduação da área da saúde", publicado na Revista Olho Mágico, disponível em http://www.ccs.uel.br/ olhomagico/n16/home.htm . 
expressa nessas diretrize ${ }^{\text {iv }}$, teve como premissa a atuação em equipe, em um sistema descentralizado, hierarquizado de referência e contra-referência recebeu influências do SUS, da Constituição de 1988 e da Lei Orgânica de Saúde no 8.080 de 1990. Outro fator importante a ser destacado é que no momento da publicação em 7 de agosto do 2001 do Parecer CNE $1.133^{8}$, da Câmara de Educação Superior que tratou Diretrizes Curriculares Nacionais dos Cursos de Graduação em Enfermagem, Medicina e Nutrição.

Esse Parecer definiu o objeto das diretrizes curriculares a partir da articulação entre a Educação Superior e a Saúde, objetivando a formação geral e específica dos egressos/profissionais com ênfase na promoção, prevenção, recuperação e reabilitação da saúde, indicando as competências comuns gerais para esse perfil de formação contemporânea dentro de referenciais nacionais e internacionais de qualidade. Os profissionais devem nessa perspectiva serem capazes de atuar com qualidade, eficiência e resolutividade, no SUS, considerando o processo de Reforma Sanitária Brasileira. ${ }^{8}$

Stella e Puccini ${ }^{9}$ analisam que essas diretrizes se constituem em uma mudança paradigmática na formação dos currículos dos profissionais saúde, pois deixam de se centrar em um modelo flexneriano, biomédico e curativo para desenvolver estruturas curriculares que enfocam o binômio saúde-doença em seus diferentes níveis de atenção. Colocam ainda que as ações depromoçãoe prevençãoemeducação e saúde na perspectiva da integralidade

\footnotetext{
iv As diretrizes curriculares para os cursos da área da saúde foram aprovadas entre 2001 e 2004. As resoluções dos cursos de Medicina, Enfermagem, Nutrição são de 2001, Farmácia, Fonoaudiologia, Fisioterapia, Odontologia de 2002, Biomedicina, Medicina Veterinária de 2003 e Educação Física de 2004. Em 2014, baseada na Lei 12.871, de 22 de outubro de 2013, que cria o Programa Mais Médicos, são promulgadas as novas diretrizes para os cursos de Medicina.
}

da assistência devem ser trabalhadas em currículos flexíveis modulares dirigidos para aquisição de um perfil, com habilidades e competências profissionais que possam contemplar tanto o individual quanto o coletivo, em diferentes metodologias de aprendizagem em múltiplos cenários de ensino. ${ }^{9: 53}$

Nesse sentido, de acordo com o contexto da época de criação, as diretrizes para a área da saúde foram definidas dentro de um contexto em que sua modulação se dava a partir dos interesses e orientações do sistema público de saúde, público, democrático garantindo a busca pela universalidade e integralidade da atenção. ${ }^{10,11,12,13}$

Nessa perspectiva as diretrizes curriculares da área da saúde para os seus respectivos cursos de graduação são também um conjunto de indicações que servem de referência para os processos de avaliação de cursos. $^{7}$

No Brasil a busca pelos padrões de qualidade na educação superior, expressos na Constituição de 1988 desembocaram em uma série de ações que originaram o atual Sistema Nacional de Avaliação da Educação Superior - SINAES. ${ }^{14,15}$ Embora bastante tensionado pelas diferenças existentes entre as IES, principalmente quanto a sua categoria administrativa (pública ou privada) e sua organização acadêmica (universidades, centros universitários ou faculdades), a proposta do SINAES visa constituir um efetivo sistema integrador, com informações e análises dos resultados das IES, dos cursos e do desempenho dos estudantes permitindo assim a construção e efetivação de políticas educativas de abrangência nacional e também no âmbito institucional formuladas no interior de cada IES.

Nessa perspectiva, a avaliação como um processo dinâmico exige uma permanente mediação pedagógica, fazendo com que o órgão estatal responsável 
pela implementação do SINAES, que é o Instituto Nacional de Estudos e Pesquisas Anísio Teixeira (INEP) acompanhe e revise periodicamente seus procedimentos e instrumentos em consonância com os princípios formativos e pressupostos da qualidade, sempre estabelecendo relações de aproximação conceitual entre avaliador e avaliado.

Após a avaliação realizada por uma comissão de avaliadores graduados na área, o relatório produz um conceito de curso, que é utilizado pela regulação como referencial básico de qualidade.

O objetivo deste estudo analisar o perfil da formação profissional dos profissionais da área da saúde ${ }^{v}$ descrita nas diretrizes curriculares nacionais e seus impactos na avaliação in loco prevista pelo SINAES. Tal abordagem tem como base o resultado das avaliações realizadas nos cursos de Medicina, Enfermagem, Nutrição, Farmácia, Fonoaudiologia, Fisioterapia, Odontologia, Biomedicina e Educação Física (bacharelado), nos anos de 2012 a 2014. Esse estudo é um recorte de uma tese de doutorado desenvolvida no Programa de Pós Graduação Stricto Sensu de Ciências e Tecnologias da Saúde, da Universidade de Brasília.

\section{Método}

Este estudo se pautou por dois momentos: a) análise documental a partir das Resoluções que estabelecem as diretrizes de cada um dos cursos: Biomedicina, Enfermagem, Farmácia,

\footnotetext{
v Os cursos de bacharelado da área da saúde, de acordo com a Resolução CNS n 278 de 8/10/1998, são: Assistência Social; Biologia; Biomedicina; Educação Física; Enfermagem; Farmácia; Fisioterapia; Fonoaudiologia; Medicina; Medicina Veterinária; Nutrição; Odontologia; Psicologia; Terapia Ocupacional. Para este estudo será enfocado o processo de avaliação in loco dos cursos que envolvem a saúde humana.
}

Fisioterapia, Fonoaudiologia, Medicina, Nutrição, Odontologia e Terapia Ocupacional e Educação Física. A escolha se deve a comparação dos artigos 4 을 e 50 das diretrizes que é comum ao grupo de profissões que integram as Ciências da Saúde, correspondendo às Competências e Habilidades Gerais da Profissão ("campo" da saúde) e as Competências e Habilidades Específicas da Profissão ("núcleo" profissional no campo da saúde). Todas as profissões do grupo de Ciências da Saúde, exceto, a Educação Física, referem que as competências e habilidades profissionais específicas da profissão devem estar afetas ao sistema de saúde vigente no país, ao trabalho em equipe multiprofissional e à integralidade da atenção. b) análise do resultado das avaliações in loco dos respectivos cursos, tendo como foco os indicadores do instrumento de avaliação de cursos que traduzem os elementos básicos de estruturação das diretrizes da área da saúde como objetivos do curso, perfil do egresso; os conteúdos curriculares; os estágios $e$ as atividades complementares, metodologia, estrutura curricular, acompanhamento e avaliação.

O desenho do estudo demanda a utilização de dados secundários, obtidos via Diretoria de Avaliação da Educação Superior (DAES), em dezembro de 2014. Foram gerados da base de informações do sistema eletrônico e-MEC, referentes à 1048 avaliações in loco dos atos autorizativos de autorização, reconhecimento e renovação de reconhecimento, ocorridas de 2012 a 2014 para os cursos Biomedicina, Enfermagem, Farmácia, Fisioterapia, Fonoaudiologia, Medicina, Nutrição, Odontologia e Terapia Ocupacional e Educação Física.

$O$ instrumento adotado para as avaliações de cursos é o Instrumento de Avaliação de Cursos de Graduação (IACG 2012) $)^{16}$ presencial e a distância adotado até abril de 2015, disponível na íntegra em (www.inep.gov.br). O IACG 2012 é 
composto por 63 indicadores, divididos em três dimensões: organização didáticopedagógica (22 indicadores), corpo docente e tutorial (20) e infraestrutura (21). Além dos indicadores há uma seção referente aos requisitos legais e normativos. ${ }^{17}$

Os procedimentos de aplicação, previstos pelo SINAES, consistem em realizar uma avaliação na IES para investigar o curso a partir de documentos apensados antecipadamente em formulário eletrônico próprio para esse fim, de documentos relevantes disponibilizados na ocasião da visita, da análise crítica às instalações e de entrevistas com interlocutores chave ao processo. Com base nas informações obtidas os avaliadores, que atuam em pares, preenchem 0 instrumento, indicador a indicador, em uma escala intervalar de cinco conceitos, sendo 1 o mínimo da escala e 5 o máximo, a média dos valores inseridos por dimensão formam o conceito da dimensão. Os conceitos 3, 4 e 5 são considerados satisfatórios pelo SINAES. Uma média ponderada dos conceitos das dimensões, com peso diferenciado em função do ato autorizativo, formam o conceito final que tem arredondamento para se enquadrar numa escala categórica de cinco pontos. Assim, é por meio das escalas e das descrições dos avaliadores, baseadas nas observações in loco e nos estudos das documentações, que os aspectos objetivo e subjetivo da avaliação se comunicam e são descritos qualitativamente.

Após realizamos a análise de conteúdo, conforme Bardin ${ }^{18}$ dessas das diretrizes de cada curso que foi sistematizada em três etapas básicas, definidas por Triviños ${ }^{19}$ assim realizadas: pré-análise, descrição analítica e interpretação referencial. Na etapa de pré-análise, para verificar os conceitos que construíram as diretrizes curriculares dos cursos da saúde que tem com foco uma formação generalista, foram analisados os artigos comuns das resoluções dos cursos de Biomedicina, Enfermagem, Farmácia, Fisioterapia, Fonoaudiologia, Medicina,
Nutrição, Odontologia e Terapia Ocupacional e Educação Física. Os artigos comuns na formação são os cinco primeiros, que foram selecionados para essa análise, tendo como parâmetros os conceitos integralidade, universalidade e equidade.

Devido ao objetivo do presente estudo, foi feito um recorte para trabalhar os resultados referentes ao perfil profissional, na Organização Didático Pedagógica (Dimensão 1), retirados os indicadores exclusivos da medicina e que não se relacionassem com a área de saúde. Uma vez que se buscou identificar a existência de diferença significativa nos escores dados para cada indicador individualmente, adotando como variáveis preditoras os cursos e os atos autorizativos, primeiramente foram analisados como os dados se comportam por meio de medidas de tendência central (média, mediana, moda) e de dispersão (desvio-padrão e variância). Foram analisados apenas os indicadores do IACG 2012 que tivessem relação com o perfil profissional: 1.3 objetivos do curso, 1.4 perfil do egresso, 1.5 estrutura curricular, 1.6 conteúdos curriculares, 1.7 metodologia, 1.8 estágio curricular supervisionado, 1.9 atividades complementares e 1.17 processos de avaliação da aprendizagem.

\section{Resultados e Discussão}

Para verificar as competências comuns que compõem a formação profissional e o perfil construído nas diretrizes propostas para os diversos cursos da área da saúde, bem como na Lei Orgânica 8080/19905, foi necessária a comparação dos artigos pertinentes à formação profissional e aos princípios doutrinários do SUS presentes nesses textos, por vezes expressos de maneiras diferentes, em diferentes pontos e com termos diferentes. 
As diferenças entre as Diretrizes que trabalham em formas diversas de redação a apropriação do SUS no país, a experiência da atenção integral a saúde e aprendizagem do trabalho em equipe. ${ }^{2}$

O perfilhamento de todas as diretrizes para a área de saúde demonstram diversidade de redação elação ao perfil do egresso. A Educação Física é a única profissão da tabela de áreas que não tem texto igual às demais profissões do grupo, mas refere quanto ao seu campo de saberes e ações as perspectivas da prevenção de problemas e agravos à saúde e a promoção, proteção e reabilitação da saúde. A formação do enfermeiro deve atender as necessidades sociais da saúde, com ênfase no SUS e assegurar a integralidade da atenção e a qualidade e humanização do atendimento. Já a formação do farmacêutico deverá contemplar as necessidades sociais da saúde, a atenção integral da saúde no sistema regionalizado e hierarquizado de referência e contrareferência e o trabalho em equipe, com ênfase no SUS. A formação do nutricionista deve contemplar as necessidades sociais da saúde, com ênfase no SUS. E a formação do biomédico, fisioterapeuta, fonoaudiólogo, médico, odontólogo e terapeuta ocupacional devem contemplar o sistema de saúde vigente no país, a atenção integral da saúde num sistema regionalizado e hierarquizado. ${ }^{20,21,22,23,24,25,26,27,28}$

As diretrizes curriculares nacionais dos cursos de graduação na área da saúde apontam, como necessidade, a formação generalista, humanista, crítica e reflexiva dos profissionais das diversas áreas da saúde. Porém, em 2014, as diretrizes da Medicina foram modificadas a partir da Lei no 12.871 , de 22 de outubro de 2013, modificando todas as competências de formação, mas manteve no perfil, no artigo 3 ㅇ a formação generalista:
O graduado em Medicina terá formação geral, humanista, crítica, reflexiva e ética, com capacidade para atuar nos diferentes níveis de atenção à saúde, com ações de promoção, prevenção, recuperação e reabilitação da saúde, nos âmbitos individual e coletivo, com responsabilidade social e compromisso com a defesa da cidadania, da dignidade humana, da saúde integral do ser humano e tendo como transversalidade em sua prática, sempre, a determinação social do processo de saúde e doença. ${ }^{29}$

Talvez essa modificação tenha ocorrido porque a Lei $n$ o 12.871/2014 que estabelece - Programa Mais Médicos, coloque a importância da formação desde o primeiro ano do curso em diferentes contextos do trabalho em saúde, traduzindo a excelência da prática médica, prioritariamente nos cenários do SUS.

Após a análise documental foi realizada a busca pelos resultados da avaliação in loco pelo SINAES indicadores do instrumento de avaliação de cursos (IACG 2012). Nessa perspectiva foram escolhidos os indicadores que traduzem os elementos básicos de estruturação das diretrizes da área da saúde como objetivos do curso, perfil do egresso; os conteúdos curriculares; os estágios e as atividades complementares, metodologia, estrutura curricular, acompanhamento $e$ avaliação. Dos 1048 relatórios analisados foram verificados os indicadores acima mencionados dos cursos de Biomedicina - BIO (83), Educação Física - EDFIS (268), Enfermagem - ENF (229), Farmácia FAR (110), Fisioterapia - FISIO (111), Fonoaudiologia - FONO (15), Medicina MED (72), Nutrição - NUT (97), Odontologia ODONT - (55) e Terapia Ocupacional - TO (8).

De maneira global observou-se que os resultados médios dos indicadores ficaram em torno do valor 3 (Tabela 1). 
Tabela 1 - Médias e Desvios-padrão por indicador

\begin{tabular}{ccc}
\hline & MÉDIA & DESVIO PAD \\
\hline 1.3 & 3,37 & 0,16 \\
\hline 1.4 & 3,41 & 0,21 \\
\hline 1.5 & 3,14 & 0,18 \\
\hline 1.7 & 3,33 & 0,11 \\
\hline 1.8 & 3,27 & 0,19 \\
\hline 1.9 & 3,24 & 0,11 \\
\hline 1.17 & 3,5 & 0,1 \\
\hline
\end{tabular}

Fonte: DAES/INEP, 2014.

Esse conceito é o primeiro nível satisfatório do SINAES e se remete ao que está descrito nas diretrizes dos cursos da área, portanto o seu cumprimento atesta que o curso atendeu às diretrizes, mas não aborda o grau de excelência .

Nos indicadores 1.5 e 1.6 que tratam respectivamente sobre a estrutura curricular e os conteúdos curriculares encontramos a média de conceito 2 para os cursos de Fisioterapia e Educação Física. Chama a atenção, nos indicadores analisados é que nenhum alcança a média do conceito 4.

O indicador 1.3 do IACG 2012 enfoca os objetivos do curso e verifica se estão em coerência com o projeto pedagógico e tem como critérios de análise o perfil profissional do egresso, estrutura curricular e contexto educacional.

Esse indicador tem com base a construção do conceito de perfil profissional articulado com a estrutura do projeto pedagógico e a justificativa que explica o porquê da proposição do curso, sua implementação e sua consolidação em relação as diretrizes.

Os resultados encontrados para esse indicador apontam para o cumprimento das diretrizes, pois a média dos conceitos está em torno do valor 3.

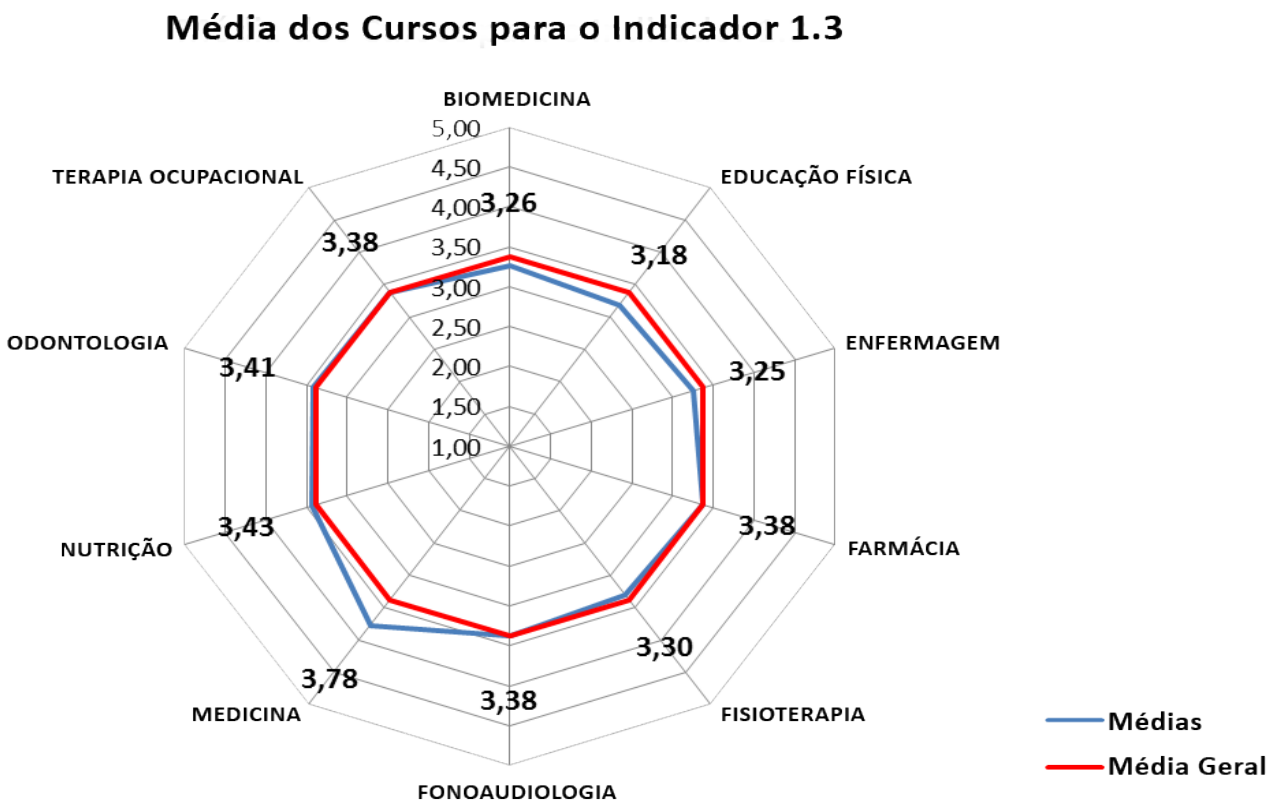

Figura 1: Resultados da média do indicador 1.3 Objetivos do curso - IACG 2012 


\section{Artigo Original}

Esses dados, porém, demonstram pouca inovação em relação ao processo de construção dos PPCs. O estudo de Lopes Neto e seus colaboradores ${ }^{30}$, sobre o processo de avaliação dos cursos da área da saúde nos primeiros anos de implementação do SINAES, aponta para evidências de que a construção e re-construção de PPC, em grande parte das IES, estão restritas à adesão aos termos que integram as DCN. Porém não se verificou a descrição da contextualização das condições de saúde da população em relação a rede de serviços de saúde, da identidade do curso, assim como do perfil do egresso afinado às necessidades sociais e sanitárias, locais e regionais. ${ }^{30: 46}$ Dos instrumentos utilizados em 2008 para o IACG 2012 houve uma sensível mudança, verificada pelos valores médios obtidos denotando um amadurecimento para o cumprimento dos critérios de análise desse indicador.

O indicador 1.4 verifica o perfil de egresso e suas competências, que devem ser avaliadas de acordo com as diretrizes da saúde. $\mathrm{O}$ artigo 4 ㅇ traz as mesmas competências gerais para área como a atenção à saúde, a tomada de decisões, a comunicação, a liderança, a administração e o gerenciamento e a educação permanente. ${ }^{8}$

\section{Média dos Cursos para o Indicador 1.4}

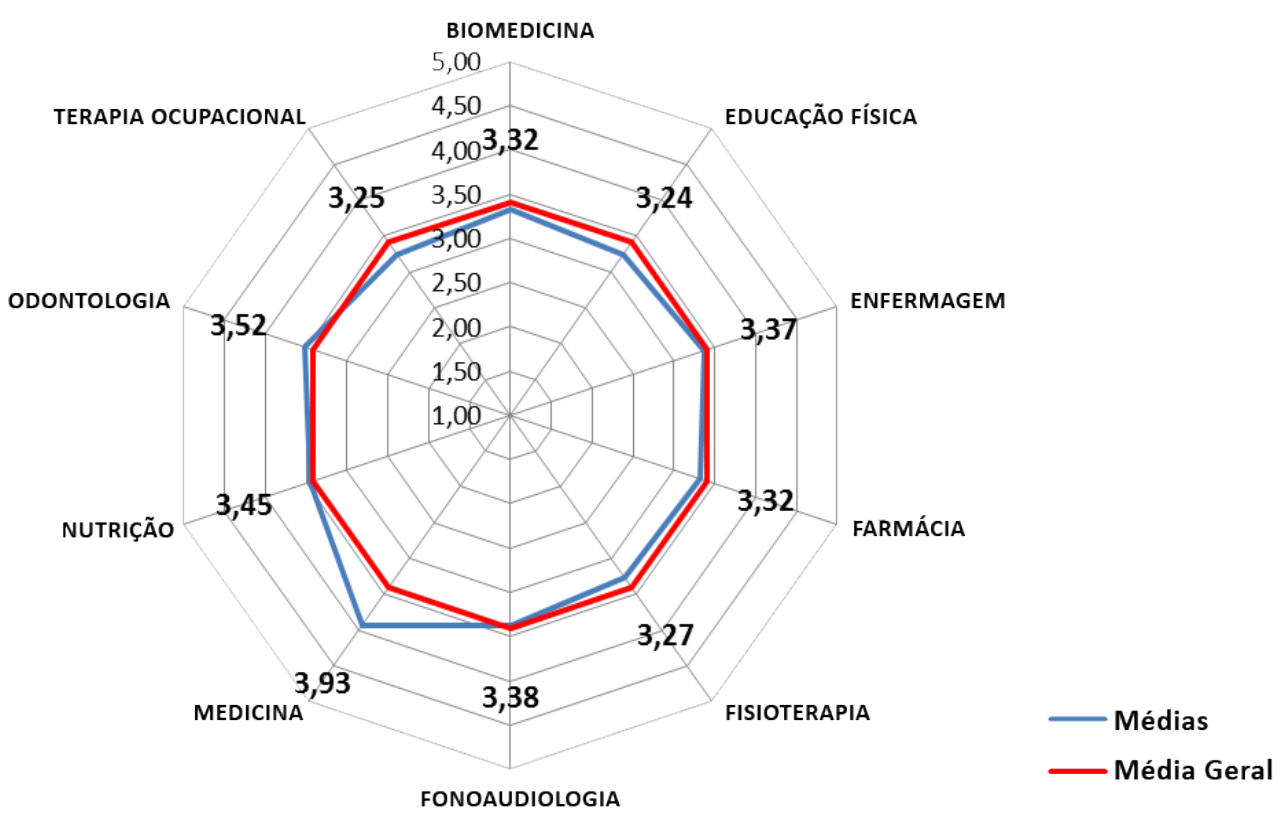

Figura 2: Resultados da média do indicador 1.4 Perfil do Egresso - IACG 2012

Os resultados encontrados nesse indicador sugerem novamente o cumprimento das diretrizes e os esforços dos cursos em traçar o perfil do egresso alinhados às competências comuns da formação do profissional de saúde. Esse desenho pode ser o resultado também da implementação da política de educação permanente prevista pelo Ministério da Saúde. ${ }^{31}$

O indicador 1.5 avalia a estrutura curricular tendo como critérios de análise a flexibilidade, interdisciplinaridade, compatibilidade da carga horária total (em horas), articulação da teoria com a prática. 
Média dos Cursos para o Indicador 1.5

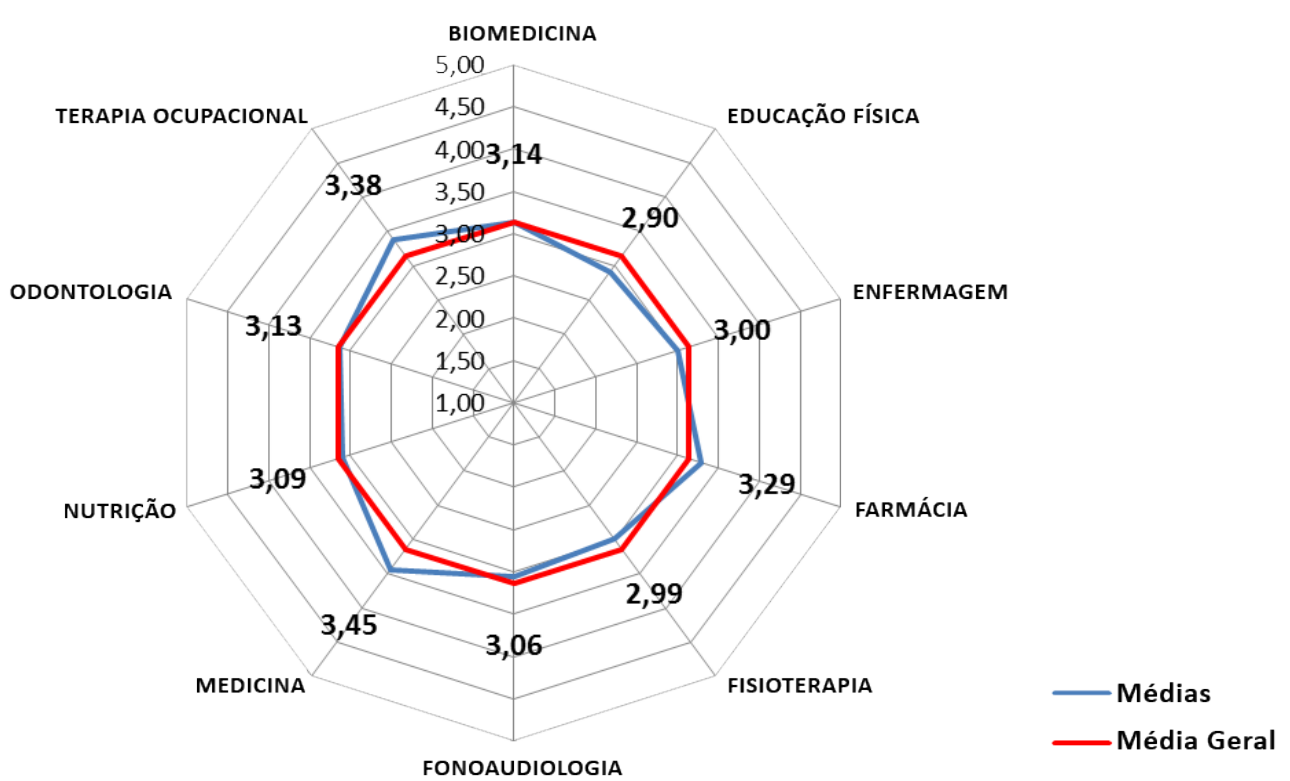

Figura 3: Resultados da média do indicador 1.5 Estrutura Curricular - IACG 2012

Os resultados encontrados das médias dos cursos de Medicina, Nutrição, Odontologia, Terapia Ocupacional, Biomedicina, Fonoaudiologia e Farmácia apontam para o conceito 3, o que sugere articulação entre o que está proposto nas diretrizes e a concepção dos projetos pedagógicos avaliados.

Entre os cursos que tem a média em torno de 3, as maiores estão entre os cursos de Medicina e Terapia Ocupacional. Chama atenção que os cursos de Fisioterapia e Educação Física, médias em torno do valor 2 . Uma importante discussão a ser realizada nesse indicador nos remete as questões pertinentes de como esses resultados sugerem um olhar sobre a relação da construção da matriz curricular dos cursos com elementos extraídos das diretrizes, porém com características de grade curricular, isto é, com uma relação estática de disciplinas e cargas horárias sem coerência com a base epistemológica que fundamenta esses elementos com os princípios do SUS, a flexibilização currículo e a formação em serviço.

O indicador 1.6 analisa os conteúdos curriculares tendo como critério de análise o desenvolvimento no currículo dos cursos do perfil do profissional considerando os aspectos: atualização, adequação das cargas horárias (em horas) e adequação da bibliografia. 
Média dos Cursos para o Indicador 1.6

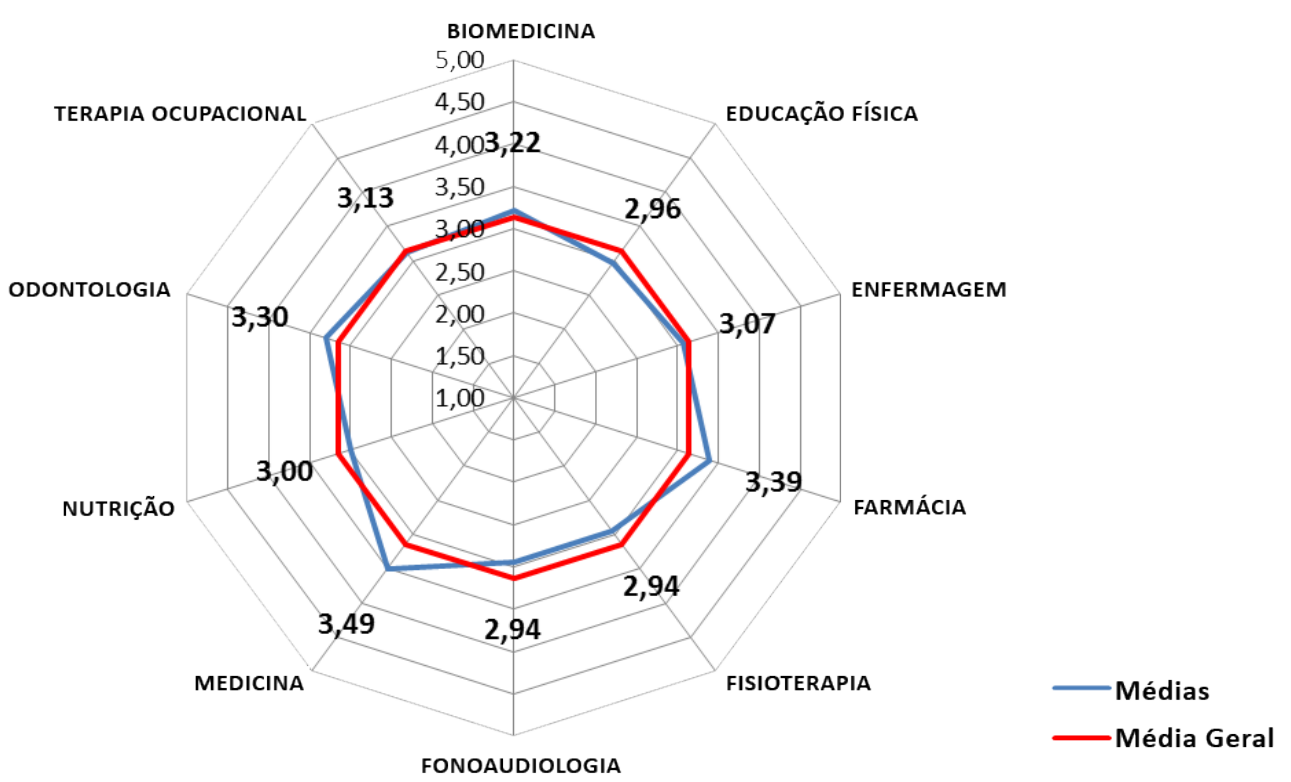

Figura 4 Resultados da média do indicador 1.6 Conteúdos Curriculares - IACG 2012

Na concepção das diretrizes e na construção do instrumento de avaliação, ao logo da história do SINAES, os indicadores 1.5 e 1.6 tem articulação e são importantes para uma análise transversal dos currículos. Em relação aos resultados encontrados na área da saúde verificamos uma veracidade nessa informação pois o quadro de médias permanece o mesmo inclusive em relação aos cursos e aos conceitos 3 e 2. Em relação ainda ao perfil e o processo de formação para a integralidade do SUS relacionado com as ações para a construção de currículos podemos evidenciar nos resultados encontrados a necessidade de consolidação por parte dos cursos do conceito de que a formação em saúde tem consonância com o atendimento aos interesses públicos no cumprimento das responsabilidades de formação acadêmico-científica, ética e humanística com vistas ao desempenho interdisciplinar e técnico nessa área. ${ }^{3,32: 208}$ Os cursos de Medicina e Odontologia tem as maiores médias, dentro do conceito 3.

O indicador 1.7 enfoca como as atividades pedagógicas estão previstas e a coerência com a metodologia prevista no projeto pedagógico do curso. Nesse gráfico, os dados do indicador, demonstram homogeneidade em relação a média geral que atribuiu o conceito 3 nas avaliações realizadas. 


\section{Média dos Cursos para o Indicador 1.7}

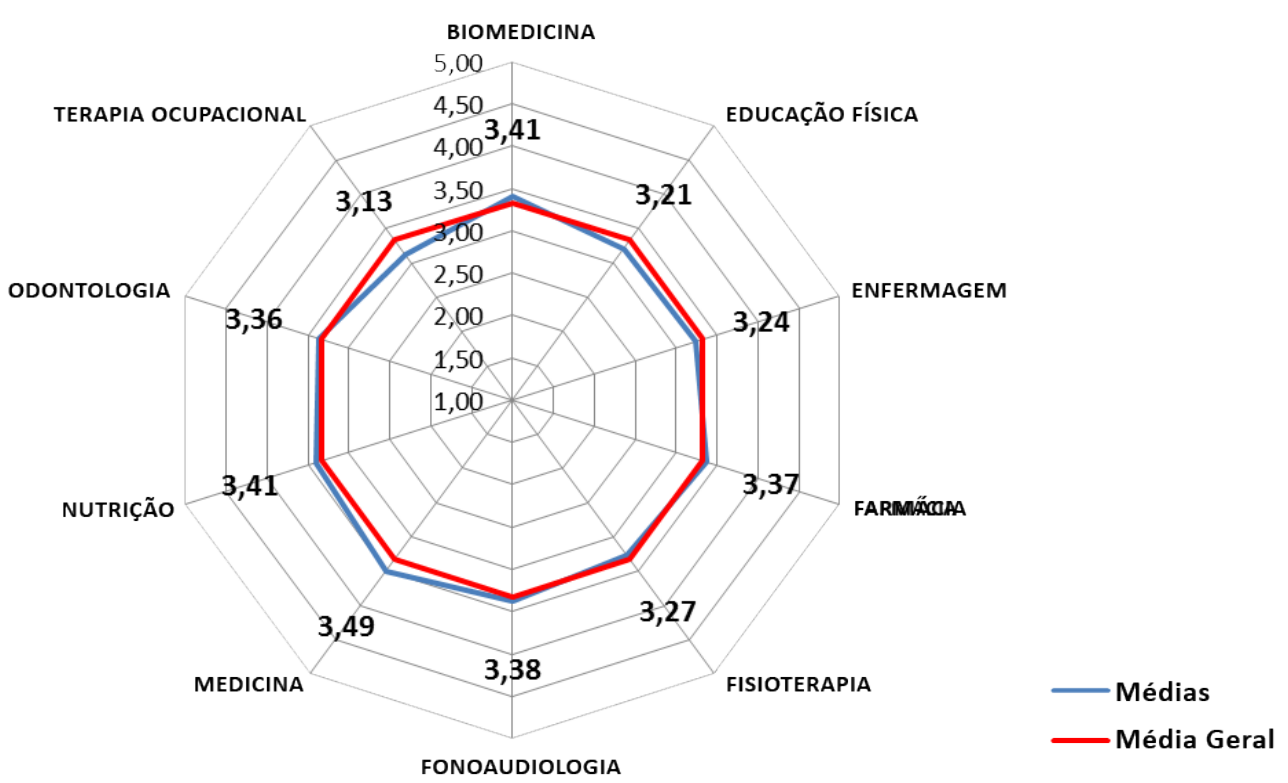

Figura 5 Resultados da média do indicador 1.7 Metodologia - IACG 2012

A homogeneidade na formação encontrada nas avaliações pode estar baseada no Parecer CNE 1.133 de 2001 que dispõe sobre o tema colocando sobre aspectos alunos dos cursos de graduação em saúde devem ter o desenvolvimento de competências e habilidades ao longo do currículo. Essas competências e habilidades são enfatizadas nas diretrizes, conforme os preceitos da Conferência Mundial sobre o Ensino Superior ${ }^{33}$ visando a capacidade de aprender a aprender que engloba aprender a ser, aprender a fazer, aprender a viver juntos e aprender a conhecer, garantindo a capacitação e profissionais com autonomia e discernimento para assegurar a integralidade da atenção e a qualidade e humanização do atendimento prestado aos indivíduos, as famílias e as comunidades. Entre os cursos que tem a média de conceito 3 as maiores estão entre os cursos de Medicina, Nutrição e Biomedicina.

$O$ indicador 1.8 verifica as condições de oferta do estágio curricular tendo como critérios de análise carga horária, previsão/existência de convênios, formas de apresentação, orientação, supervisão e coordenação. Na faixa do conceito 3 o curso de Fisioterapia apresentou a média geral mais baixa. Há variação entre as médias e as médias gerais dos cursos de Medicina, Fisioterapia, Fonoaudiologia, Farmácia e Biomedicina. Essa variação pode estar associada as questões relacionadas a flexibilização prevista para o estágio e as competências e habilidades específicas da profissão. ${ }^{3,32: 209}$ 
Média dos Cursos para o Indicador 1.8

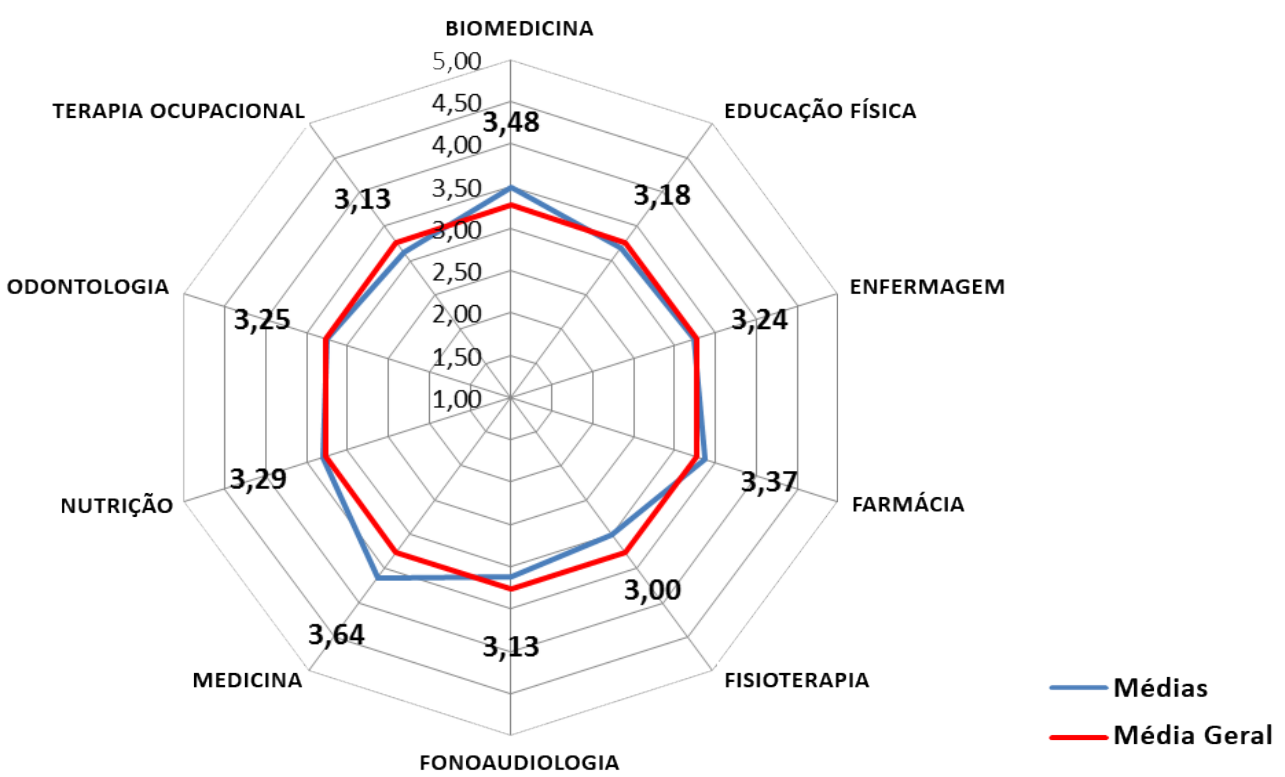

Figura 6 Resultados da média do indicador 1.8 Estágio Curricular Supervisionado - IACG 2012

O indicador 1.9 verifica as atividades complementares e tem como critério de análise previsão/implementação, regulamentação/ institucionalização, carga horária, diversidade de atividades e formas de aproveitamento. Esse indicador também tem relação com o processo de flexibilização do currículo, pois incorpora as atividades complementares na organização do curso e tem coerência com a concepção utilizada nos estágios curriculares. ${ }^{30: 47}$

\section{Média dos Cursos para o Indicador 1.9}

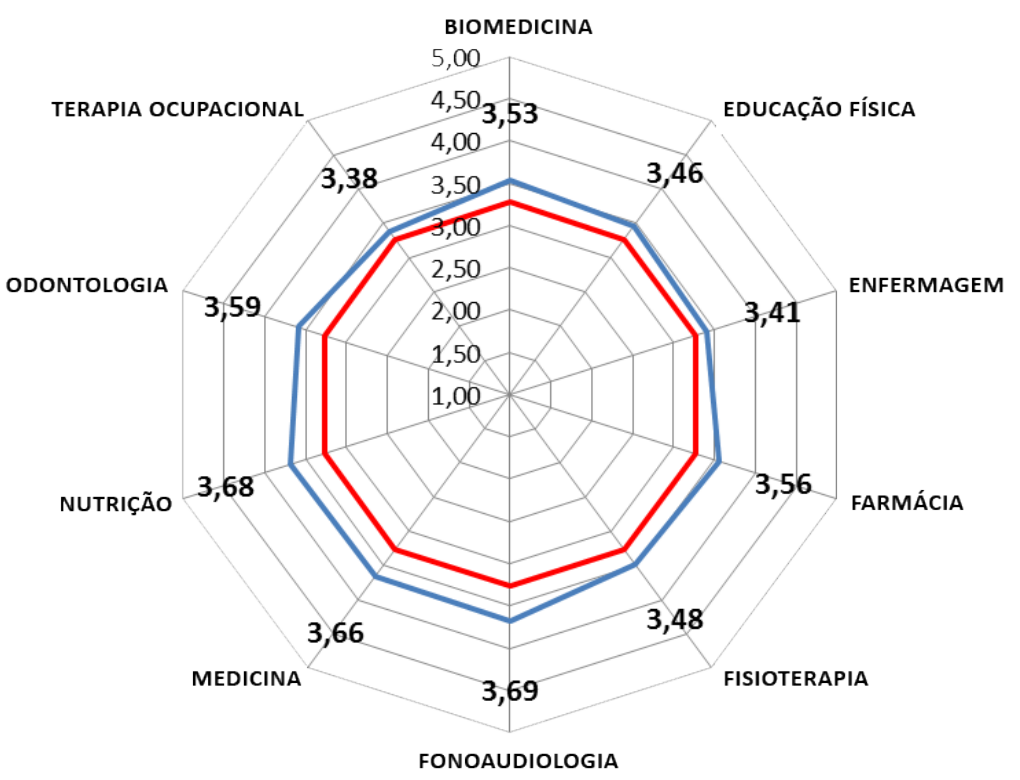




\section{Artigo Original}

Em relação aos resultados encontrados no indicador 1.9 observamos a maior variação entre as médias por curso e a média geral. A Fonoaudiologia tem o maior valor de média encontrado, seguido da Nutrição e da Medicina. Tal situação pode ocorrer semelhante ao comportamento encontrado no indicador 1.8 , pois os dois se complementam no processo de organização do projeto pedagógico do curso e demonstram muitas particularidades uma vez que também enfocam as habilidades específicas da profissão.

$O$ indicador 1.17 enfoca os procedimentos de avaliação previstos/implantados utilizados nos processos de ensino-aprendizagem atendem, de maneira suficiente, à concepção do curso definida no seu Projeto Pedagógico do Curso - PPC.

\section{Média dos Cursos para o Indicador 1.17}

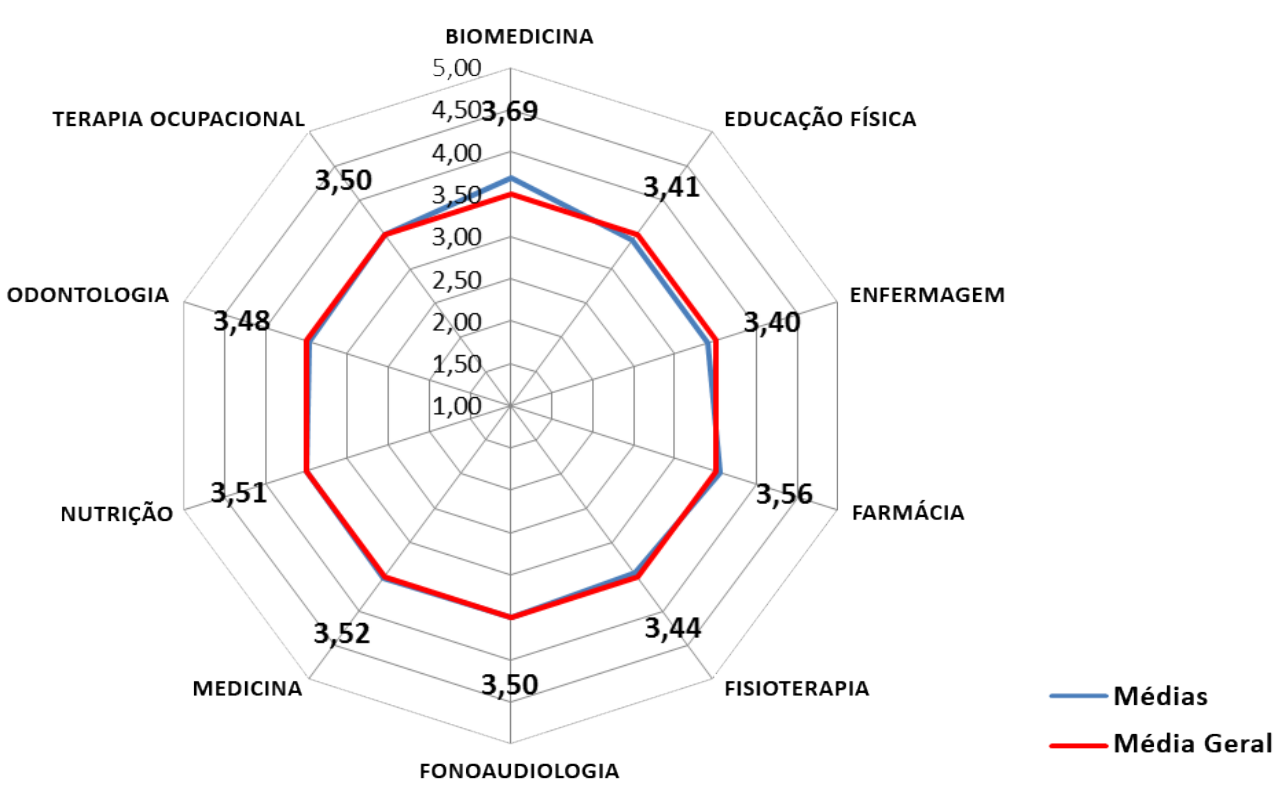

Figura 8 Resultados da média do indicador 1.17 Procedimentos de Avaliação do Processo Ensino Aprendizagem - IACG 2012

Nesse indicador as medias dos cursos e médias gerais apresentam pouca variação, sendo que Biomedicina tem a maior média, seguida por Farmácia e Medicina.

$\mathrm{O}$ curso de Medicina tem as maiores médias em quase todos indicadores em relação aos outros cursos, exceto nos indicador 1.9 Atividades Complementares e 1.17 Avaliação dos Processos de Ensino Aprendizagem.

As diferenças significativas encontradas em relação ao curso de Medicina, no instrumento IACG 2012, talvez possam estar associadas ao fato de que esse curso, como o de Odontologia, passem por processo de autorização, conforme Art. 28 do Decreto no 5.773/2006. Ao compararmos os indicadores dos cursos de Odontologia e Medicina verificamos que as diferenças significativas permanecem, porém não constatamos diferenças entre os indicadores de Odontologia e os outros cursos.

Por outro lado, uma vez que as diretrizes são comuns para todos os cursos, é possível que a Medicina apresente diferenças significativas porque os projetos pedagógicos estejam melhor estruturados. Isso é factível uma vez que no período anterior ao do IACG 2012 
havia instrumentos específicos para os diferentes atos autorizativos desse curso, nos quais avaliador tinha que se posicionar na dimensão 1 , no relato global sobre da categoria projeto pedagógico do curso sobre a formação médica. ${ }^{34: 8}$ Tal indução pode ter produzido projetos pedagógicos específicos em acordo com as Diretrizes Curriculares Nacionais, além de fornecer elementos para a política de expansão específica do Ministério da Educação para os cursos de Medicina.

\section{Considerações finais}

Após 11 anos de implementação do SINAES, de 14 anos de implementação das diretrizes, a avaliação in loco se estabeleceu como a ferramenta de verificação das condições de oferta e qualidade do curso, induzindo qualidade na educação superior do país.

Em especial na área da saúde com advento das diretrizes que tem no SUS o processo de formação como eixo central para a melhora da saúde da população, a organização dos serviços, a articulação entre o sistema de saúde, suas várias esferas de gestão e as instituições formadoras.

Tal proposta centra a avaliação in loco como indutora da qualidade, por meio de instrumento matricial, que avalia os cursos em seus diferentes momentos e coloca em evidência a formação para a área da saúde como construção da educação em serviço/educação permanente em saúde, agregando o desenvolvimento individual e institucional, os serviços, a atenção à saúde e o controle social.

Todos os resultados encontrados na pesquisa evidenciam a importância da consolidação de um perfil comum para a integralidade da assistência, do trabalho humanizado e em equipe no SUS. ${ }^{35,36,37,30}$
Desse processo avaliativo, articulado com mecanismos regulatórios do Estado, decorrem medidas de natureza corretiva e planos de expansão qualificados que assegurem o desenvolvimento da educação superior, em patamares compatíveis com os padrões mínimos de qualidade para a oferta de cursos de graduação, orientados pelas diretrizes curriculares nacionais..$^{37,30,15} \mathrm{Na}$ avaliação de cursos um conjunto de indicadores, critérios de análise são verificados in loco nas dimensões organização didático-pedagógica, corpo docente e infraestrutura. As DCN norteiam os projetos pedagógicos do curso, a construção dos indicadores e a condução do processo avaliativo. No caso das diretrizes da área da saúde o perfil tem como elementos fundamentais o conceito de saúde e os princípios e diretrizes do SUS. Uma reflexão a ser realizada em relação ao perfil comum para área, a partir dos dados encontrados, refere-se o papel da avaliação como indutora de qualidade, no processo de construção dos projetos pedagógicos, bem como a necessidade de reflexão sobre a concepção desse perfil profissional comum de acordo com os princípios do SUS, com a contextualização da formação em relação a região de saúde, com os problemas do país e as necessidades de conhecimento impostas pelo mundo moderno. 


\section{Referências}

1. Brasil. Constituição (1988). Constituição da República Federativa do Brasil. Brasília, DF: Senado Federal; 1988.

2. Ceccim RB. Educação Permanente em Saúde: desafio ambicioso e necessário. Interface: Comunicação, Saúde, Educação. 2004, Set; 9(16): 161-77.

3. Gonze GG. A integralidade na formação dos profissionais de saúde: tecendo saberes e práticas. [dissertação]. Juiz de Fora (MG): UFJF; 2009.

4. Winters JRF. Formação em enfermagem para o SUS numa perspectiva crítico e criativa: visão dos formandos [Dissertação]. São Carlos: UFSC; 2012.

5. Brasil. Lei no 8080/90 de 19 de Setembro de 1990. Dispõe sobre as condições para promoção, proteção e recuperação da saúde, a organização e o financiamento dos serviços correspondentes e dá outras providências. Diário Oficial da União. 1990 Set 19.

${ }^{6}$. Brasil. Lei 9.131, de 24 de novembro de 1995. Altera dispositivos da Lei no 4.024, de 20 de dezembro de 1961, e dá outras providências. Diário Oficial da União. 25 nov 1995.

7. Sales SR. Diretrizes curriculares. In: Oliveira DA, Duarte AMC, Vieira LMF. Dicionário: trabalho, profissão e condição docente [CDROM]. Belo Horizonte: UFMG/Faculdade de Educação; 2010.

8. Conselho Nacional de Educação. Parecer CNE/CES no 1133, de 7 agosto de 2001. Diretrizes curriculares nacionais dos cursos de graduação em enfermagem, medicina e nutrição. Diário Oficial da União. 2001 Out 3.

9. Stella RCR, Puccini RF. A formação profissional no contexto das Diretrizes Curriculares nacionais para o curso de medicina. In: Puccini RF, Sampaio LO, Batista NA. A formação médica na Unifesp: excelência e compromisso social. São Paulo: Unifesp; 2008: 53-69.

10. Feuerwerker LCM. Mudanças na educação médica e residência médica no Brasil. InterfaceComun Saúde Educ. 1998; 2(3): 51-71.

${ }^{11}$. Feuerwerker LCM. Algumas reflexões sobre o desenvolvimento do Programa UNI. Divulgação em saúde para debate. 2000, Dez; (22): 63-70.

12. Feuerwerker LCM, Sena RR. Contribuições ao movimento de mudança na formação profissional em saúde: uma avaliação das experiências UNI. Interface: comunicação, saúde, educação. 2002, Fev; 6(10): 37-50.

13. Gonzalez AD, Almeida MJ. Movimentos de mudança na formação em saúde: da medicina comunitária às diretrizes curriculares. Physis [online]. 2010; 20(2): 551-70.

14. Instituto Nacional de Estudos e Pesquisas Educacionais Anísio Teixeira. SINAES Sistema Nacional de Avaliação da Educação Superior: Da concepção à regulamentação. Brasília: INEP; 2007. 4.ed. ampl.

${ }^{15}$. Griboski CM. Regular e/ou induzir qualidade? Os cursos de Pedagogia nos ciclos avaliativos do Sinaes. [tese]. Brasília (DF): Universidade de Brasília; 2014. 


\section{Artigo Original}

16. Brasil. Instituto Nacional de Estudos e Pesquisas Educacionais Anísio Teixeira (INEP). Instrumento de Avaliação de Cursos de Graduação presencial e a distância. Brasília: INEP; 2012. Disponível em: <http://download.inep.gov.br/educacao_superior/avaliacao_cursos_ graduacao/instrumentos/2012/instrumento_com_alteracoes_maio_12.pdf>. Acesso em 08 nov 2013.

17. Funghetto SS, Griboski CM. Reformulação dos Instrumentos de Avaliação dos Cursos de Graduação da Educação Superior para Operacionalização do Sistema Nacional de Avaliação da Educação Superior - Sinaes. Nota Técnica. Brasília: INEP; 2011. Disponível em: <http://portal. inep.gov.br/web/guest/nota-tecnica1>. Acesso em: 12 jul 2015

18. Bardin, L. Análise de Conteúdo. Lisboa, Portugal: Edições 70, LDA; 2009.

19. Triviños ANS. Introdução à pesquisa em ciências sociais: a pesquisa qualitativa em educação. São Paulo: Atlas; 1987.

20. Conselho Nacional de Educação. Resolução CNE/CES 3/2001. Institui Diretrizes Curriculares Nacionais do Curso de Graduação em Enfermagem. Diário Oficial da União. 9 de Novembro de 2001. Seção 1, p.37.

${ }^{21}$. Conselho Nacional de Educação. Resolução CNE/CES 4/2001. Institui Diretrizes Curriculares Nacionais do Curso de Graduação em Medicina. Diário Oficial da União. 9 de novembro de 2001. Seção 1, p.38.

22. Conselho Nacional de Educação. Resolução CNE/CES 5/2001. Institui Diretrizes Curriculares Nacionais do Curso de Graduação em Nutrição. Diário Oficial da União. 9 de novembro de 2001. Seção 1, p.39.

${ }^{23}$. Conselho Nacional de Educação. Resolução CNE/CES 2/2002. Institui Diretrizes Curriculares Nacionais do Curso de Graduação em Farmácia. Diário Oficial da União. 4 de Março de 2002; Seção 1, p.9.

${ }^{24}$. Conselho Nacional de Educação. Resolução CNE/CES 3/2002. Institui Diretrizes Curriculares Nacionais do Curso de Graduação em Odontologia. Diário Oficial da União. 4 de março de 2002. Seção 1, p.10.

25. Conselho Nacional de Educação. Resolução CNE/CES 4/2002. Institui Diretrizes Curriculares Nacionais do Curso de Graduação em Fisioterapia. Diário Oficial da União. 4 de março de 2002. Seção 1, p.11

26. Conselho Nacional de Educação. Resolução CNE/CES 5/2002. Institui Diretrizes Curriculares Nacionais do Curso de Graduação em Fonauldiologia. Diário Oficial da União. 4 de março de 2002. Seção 1, p.12.

27. Conselho Nacional de Educação. Resolução CNE/CES 6/2002. Institui Diretrizes Curriculares Nacionais do Curso de Graduação em Terapia Ocupacional. Diário Oficial da União. 4 de março de 2002. Seção 1, p.12.

28. Conselho Nacional de Educação. Resolução CNE/CES 2/2003. Institui Diretrizes Curriculares Nacionais dos Cursos de Graduação em Biomedicina. Diário Oficial da União. 20 de fevereiro de 2003. Seção 1, p.16. 


\section{Artigo Original}

29. Conselho Nacional de Educação. Resolução CNE/CES 3/2014. Institui Diretrizes Curriculares Nacionais do Curso de Graduação em Medicina e dá outras providências. Diário Oficial da União. 23 de junho de 2014. Seção 1, p.8-11.

${ }^{30}$. Lopes Neto D, Teixeira E, Vale EG, Cunha FS, Xavier IM, Fernandes JD, Shiratori K, Reibnitz KS, Sordi MRL, Barbieri MIB. Um olhar sobre as avaliações de cursos de graduação em enfermagem. Revista Brasileira de Enfermagem. 2008; 61(1): 46-53.

31. Brasil. Ministério da Saúde. Secretaria de Gestão do Trabalho e da Educação na Saúde. Departamento de Gestão da Educação em Saúde. Política Nacional de Educação Permanente em Saúde. Brasília: Ministério da Saúde; 2009.

32. Ferreira RC, Fiorini VML, Crivelaro E. Formação profissional no SUS: o papel da Atenção Básica em Saúde na perspectiva docente. Rev. bras. educ. med. [online]. 2010; 34(2): 207-15.

${ }^{33}$. Unesco. Declaração Mundial sobre Educação Superior no Século XXI: Visão e ação. Paris: Conferência Mundial sobre Ensino Superior; 1998.

${ }^{34}$. Brasil. Instituto Nacional de Estudos e Pesquisas Educacionais Anisio Teixeira. Instrumento de Avaliação para cursos de graduação em medicina. Brasilia: INEP; 2008.

35. Fernandes JD, Ferreira SLA, Oliva DSR, Santos MP, Costa HOG. Estratégias para a implantação de uma nova proposta pedagógica na Escola de Enfermagem da Universidade Federal da Bahia. Rev Bras Enferm. 2003; 56(4): 392-5.

${ }^{36}$. Fernandes JD, Xavier IM, Ceribelli MIPF, Bianco MHC, Maeda D, RODRIGUES MVC. Diretrizes Curriculares e estratégias de implantação de uma nova proposta pedagógica. Rev Esc Enferm USP. 2005; 30(4): 443-9.

${ }^{37}$. Brasil. Ministério da Saúde. Ministério da Educação. A aderência dos cursos de graduação em enfermagem, medicina e odontologia às diretrizes curriculares nacionais. Brasília: Ministério da Saúde; 2006. 